\title{
Performance effects of massed and distributed practice upon constant and variable forms of the letter-pathways test'
}

A letter-pathways test was presented which required Ss to connect a scattered array of alphabetical letters in sequence in 5 sec. Either 10 identical problems or 10 different problems were orthogonally combined with massed and distributed practice (5 sec rest interval between each problem). Results indicated that constant forms ( 10 identical problems) were easier than variable forms (10 different problems) and that distributed practice was more facilitative than massed practice.

The Tsai-Parthington Numbers test is a perceptualmotor skills problem which requires $S$ to draw lines connecting, in numerical order, a scattered array of numbers. Several studies have investigated performance on this test as it is affected by massed vs distributed practice (Ammons, 1955; Underwood, 1961) and by repeated problems with the same array of numbers (constant form) vs a series of problems with different number arrays (variable form; Underwood, 1961). The dependent measure in this task is the total number of numbers which are correctly connected with a pencil on each successive, 30-sec problem. In the Ammons study, Ss worked on 10 problems, each with a different 25number pattern (variable form). She found that performance increased over problems and that distributed practice was facilitative. Underwood, using a generally similar paradigm, also compared distributed and massed practice as well as introducing both variable and constant problem forms. Underwood confirmed Ammons' results, finding that distributed was superior to massed practice. In addition, his study indicated that the constant forms were significantly easier than the variable forms.

The present study attempted to replicate and extend the previous findings while employing a random array of letters instead of the scattered numbers, and shorter time intervals. Two types of practice treatments, distributed vs massed practice, were orthogonally combined with two forms of the task, constant and variable. Based on previous studies, it was hypothesized that performance would improve with practice, that constant forms would be easier than variable forms, and that distributed practice would be more facilitative than massed practice.

\section{Method}

Each of 16 college Ss worked on 10 problems. Each problem consisted of the first 15 letters of the alphabet randomly scattered on a $5-1 / 2$ × $8-1 / 2$ in. page. The $S$ was allowed $5 \mathrm{sec}$ to connect with a pencil, in alphabetical order, the 15 letters in any one problem.

A 2 by 2 repeated measures design was used. Two practice treatments, massed and distributed, were orthogonally combined with two problem forms, constant and variable. In the constant condition, all 10 problems in the booklet were identical. In the variable condition, each of the 10 problems was different. For the distributed practice condition, but not for the massed practice condition, a blank page was inserted between each problem page.

Each $S$ was instructed to connect the letters in alphabetical order as quickly as possible, beginning with the letter "A," and to start on the next problem when E said "turn." The $S$ was informed that he had $5 \mathrm{sec}$ for each problem. The Ss in the distributed practice condition were instructed to "rest" 5 sec each time a blank page appeared in the booklet. At the end of this 5 sec interval, E again signaled $\mathrm{S}$ to turn to the next problem.

\section{Resulis}

In Fig. 1, the four practice-form combinations are plotted over the 10 trials. An analysis of variance showed performance in the distributed practice conditions to be significantly superior to performance in the massed practice conditions $(F=19.63, \mathrm{df}=1 / 12$, $\mathrm{p}<.01)$. Also, performance in the constant conditions was significantly better than performance in the variable conditions $(\mathrm{F}=21.50, \mathrm{df}=1 / 12, \mathrm{p}<.01)$. Performance improved significantly over trials (F $=38.28, \mathrm{df}=9 / 108, \mathrm{p}<.01$ ). Finally, the forms (constant and variable) by trials interaction was significant $(F=2.18, d f=9 / 108, p<.05)$, indicating that constant conditions of the letter-pathways test showed a more pronounced improvement with practice than did the variable conditions. Performance in the variable conditions tended to asymptote in fewer trials than in the constant conditions. For either problem form, performance under distributed practice was superior to performance under massed practice. The forms 


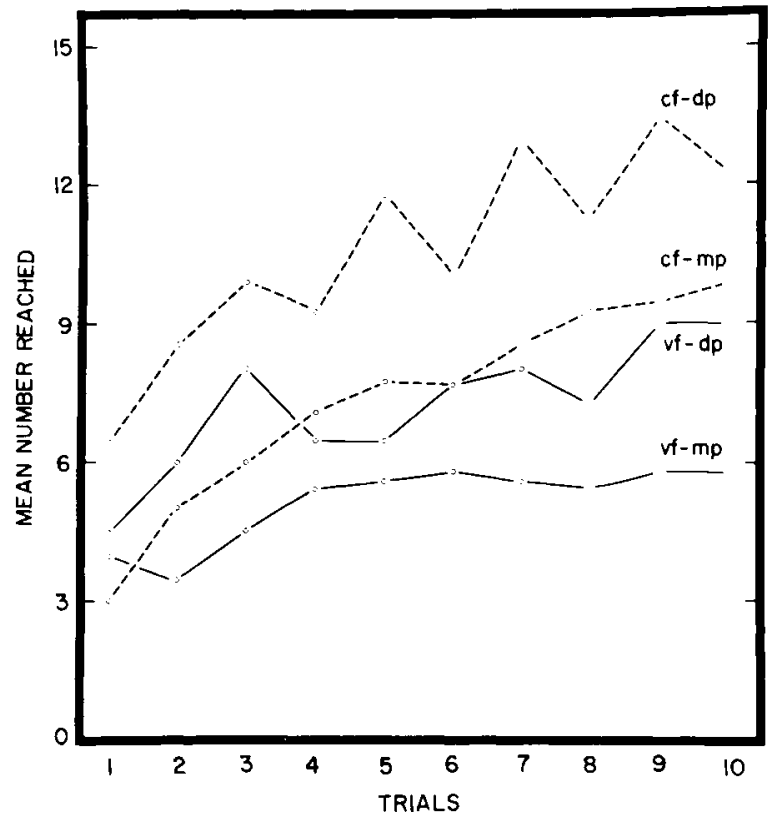

Fig. 1. Performance on the letter-pathways test as a function of constant (cf) and variable (vf) forms on successive trials, and as a function of massed (mp) and distributed (dp) practice.

by practice, the practice by trials, and the forms by practice by trials interactions did not reach statistical significance.

Discussion

The present task required $S$ to connect, in alphabetical order, a scattered array of letters. Generally, S's perceptual-motor performance was better when his 10 problems involved the same array (constant form) than when he completed 10 different problems (variable form). Also, under both constant and variable forms of the problem, performance was better with distributed practice than with massed practice.

The results, then, summarized in Fig. 1, replicate the major findings of the Underwood experiment, even though the working time in the present experiment was just $5 \mathrm{sec}$, compared to Underwood's $30 \mathrm{sec}$, the rest interval in the distributed practice condition was just $5 \mathrm{sec}$, compared with Underwood's $60 \mathrm{sec}$, and, of course, letters were used in the present study instead of numbers.

It is interesting to note that the magnitude of the difference between the variable and constant conditions in the present study were not as great as in Underwood's experiment. However, the magnitude of the difference between distributed and massed conditions was about the same for the two studies. That is, compared with the Underwood study, the speeded-up working conditions of the present experiment apparently depressed the difference between the constant vs variable forms of the problem, but did not influence the difference between massed vs distributed practice.

\section{References}

AMMONS, C. H. Task for the study of perceptual learning and performance variables. Percept. mot. Skills, 1955, 5, 11-14.

UNDERWOOD, B. J. Distributed practice on the Tsai-Parthington numbers test. Percept. mot. Skills, 1961, 12, 325-326.

Note

1. This research was performed pursuant to contract OE 5-10-154 with the United States Office of Education, Department of Health, Education, and Welfare, under the provisions of the Cooperative Research program. 